\title{
Measuring Inflation: The Core Is Rotten
}

\begin{abstract}
James Bullard
An earlier version of this article was delivered as a speech to the Money Marketeers of New York University, New York, New York, May 18, 2011.*
\end{abstract}

Federal Reserve Bank of St. Louis Review, July/August 2011, 93(4), pp. 223-33.

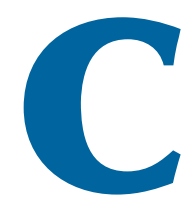

ontrolling overall inflation is a goal of monetary policy. Measures of overall, or headline, inflation attempt to include changes in the prices paid for a wide variety of goods-that is, what households actually have to pay for their daily purchases. This is a sensible notion of precisely what the central bank can and should control over the medium term.

Many discussions of monetary policy, even within the central banking community, discuss movements of subsets of prices instead of the overall or headline measure of price changes. The most famous subset is the "core"-all prices except those relating to food or energy. Core inflation is the measured rate of increase of these prices. ${ }^{1}$ Control of core inflation is not the goal of monetary policy, although it sometimes seems to be, given the amount of emphasis put on this concept in the United States.

Many of the old arguments in favor of a focus on core inflation have become rotten over the years. It is time to drop the emphasis on core

1 Figures 1 and 2 show core and headline inflation for the consumer price index (CPI) and the personal consumption expenditures (PCE) chain price index. inflation as a meaningful way to interpret the inflation process in the United States.

One immediate benefit of dropping the emphasis on core inflation would be to reconnect the Federal Reserve with households and businesses who know price changes when they see them. With trips to the gas station and the grocery store being some of the most frequent shopping experiences for many Americans, it is hardly helpful for Fed credibility to appear to exclude all those prices from consideration in the formation of monetary policy.

There are several key arguments that are commonly used to favor a focus on core inflation in monetary policy discussions. ${ }^{2}$ I will argue that all of them are essentially misguided. Because of this, the best the central bank can do is to focus on headline measures of inflation. The headline measures were designed to be the best measures of inflation available-the Fed should respect that construction and accept the policy problem it poses. Many other central banks have solidified their position on this question by adopting explicit, numerical inflation targets for headline inflation, thus keeping faith with their citizens

\footnotetext{
2 See, for instance, Mishkin (2007).
}

James Bullard is president and CEO of the Federal Reserve Bank of St. Louis. Any views expressed are his own and do not necessarily reflect the views of other Federal Open Market Committee members. The author benefited from review and comments by Cletus Coughlin, Riccardo DiCecio, William Gavin, Michael McCracken, Andrea Tambalotti, Daniel Thornton, Christopher Waller, and Jonathan Wright.

* The speech to the Money Marketeers of New York University (Bullard, 2011) can be accessed at http://research.stlouisfed.org/econ/bullard/pdf/Measuring Inflation May 182011 FINAL.pdf.

(C) 2011, The Federal Reserve Bank of St. Louis. The views expressed in this article are those of the author(s) and do not necessarily reflect the views of the Federal Reserve System, the Board of Governors, or the regional Federal Reserve Banks. Articles may be reprinted, reproduced, published, distributed, displayed, and transmitted in their entirety if copyright notice, author name(s), and full citation are included. Abstracts, synopses, and other derivative works may be made only with prior written permission of the Federal Reserve Bank of St. Louis. 
Figure 1

\section{CPI Inflation Measures: Headline and Core}

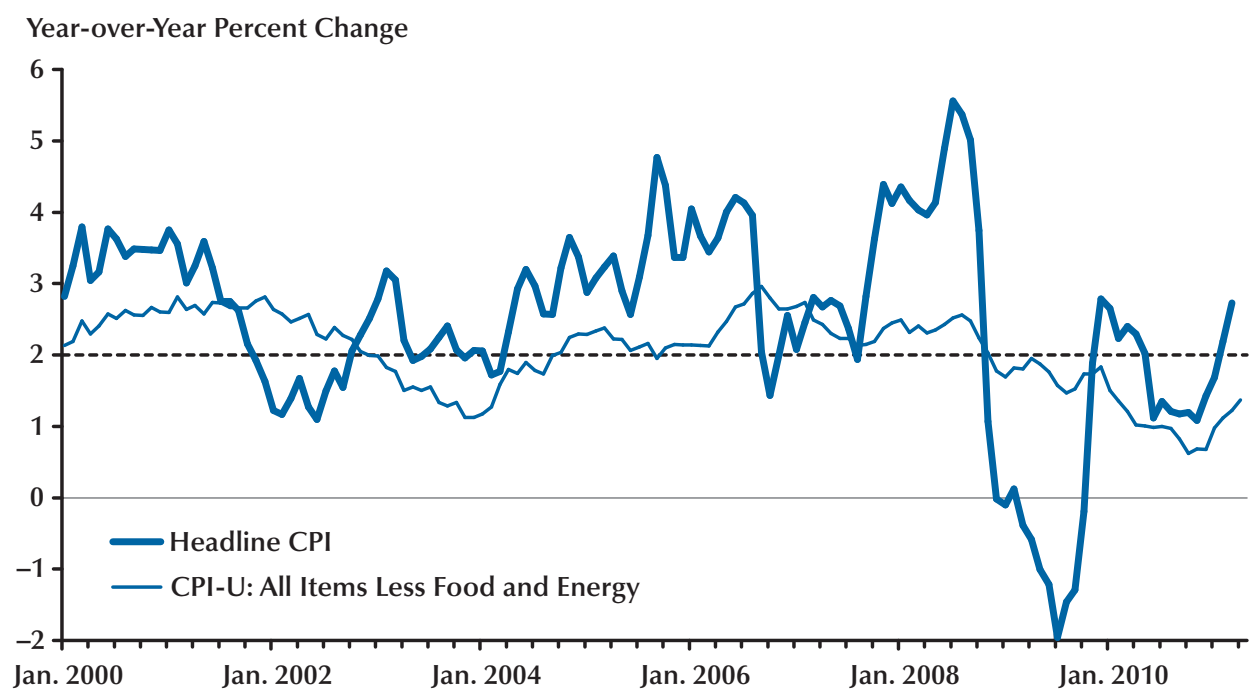

SOURCE: Bureau of Labor Statistics. Last observation April 2011.

Figure 2

PCE Chain Price Index Inflation Measures: Headline and Core

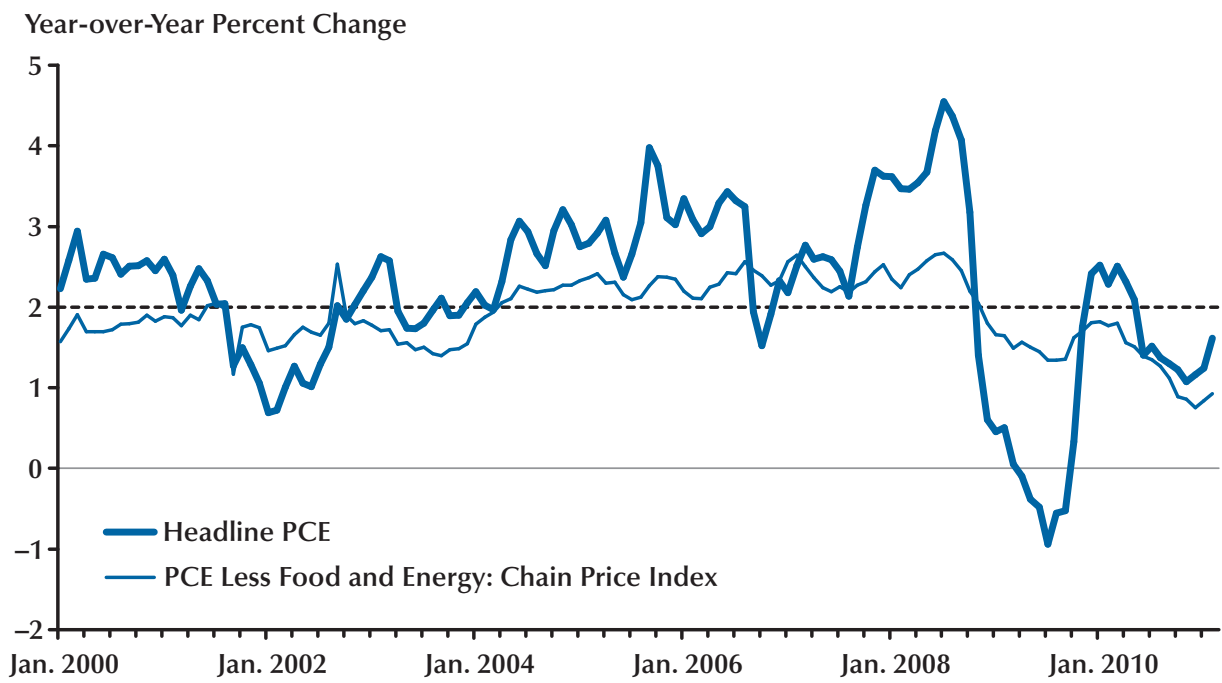

SOURCE: Bureau of Economic Analysis. Last observation April 2011. 
that they will work to keep headline inflation low and stable. The Fed should do the same.

\section{THE "VOLATILITY" ARGUMENT}

I will start with an easy one, the argument that headline inflation is more volatile than core inflation and that, therefore, if monetary policy reacts systematically to headline inflation the economy itself would become more volatile. This could also be termed the "all hell would break loose" argument.

Yes, it is true that headline inflation tends to be more volatile than subset inflation measures that exclude or downweight the most volatile components. However, I do not think this says anything about how policy should or should not react to movements in headline inflation. Any policy response can of course be adjusted appropriately to take into consideration that the price index contains a certain level of volatility. In other words, the policy response can be optimized given the inflation index being targeted. Some monetary policy simulations that I have seen in this area simply take an existing policy rule that has been designed for core inflation and use the same rule with headline inflation-resulting in increased volatility in goal variables. That type of experiment is just saying that an inappropriate policy rule will produce less-than-satisfactory results, which is hardly surprising.

One might very legitimately turn the headline volatility question on its head. With core inflation as the preferred index for monetary policy analysis, the policymaker will tend to react to relatively small movements in measured core inflation. In that case, arguably, any policy response has to be larger-possibly substantially larger-when even small changes in measured core inflation are observed in order to execute the optimal policy. This may be ill-advised to the extent that small movements in core inflation are, in fact, simply noise.

Recent experience offers something to ponder in this regard. While many think that the recent financial crisis provides an illustration of the merits of the focus on core inflation, I do not see it that way at all. During the second half of 2008 and into 2009, headline inflation measured from one year earlier fell dramatically and in fact moved into negative territory. This was a signal-one among many, to be sure-that a dramatic shock was impacting the U.S. economy. Inflation was not immune to this shock. The Federal Open Market Committee (FOMC) reacted appropriately with an aggressive easing of monetary policy. Yet the movements in core inflation during this chilling period were far more muted and sent much less of a signal that action was required.

There is also the question of the wisdom of an intermediate target strategy with respect to inflation. Since headline inflation is the goal for monetary policy, the introduction of the core inflation concept as an intermediate target introduces some slippage between the variable the Committee is reacting to and the ultimate value of the goal variable. The intermediate target strategy works as follows: The Committee makes a policy tool adjustment (such as the policy interest rate), which is designed to target core inflation, which subsequently impacts headline inflation. It is not clear that this intermediate target strategy actually maximizes policy performance with respect to the overall price index. For that, much depends on the statistical properties of the relationship between core inflation and headline inflation, and that relationship tends to change over time.

And finally on the topic of the volatility of headline inflation, the headline index can be smoothed in any number of other ways that stop short of ignoring a wide class of important prices in the economy. One simple way is to consider headline inflation measured from one year earlier, but there are many others. To the extent that the volatility of headline inflation is a problem, there are better methods of addressing that than to simply dismiss troublesome prices.

\section{THE “CORE PREDICTS HEADLINE" ARGUMENT}

One popular argument for focusing on core inflation is that core inflation is a good and con- 
sistent predictor of future headline inflation. I think this is wrongheaded, as well as wrong. Let's begin with the "wrongheaded" part. The idea that core predicts future headline is often based on univariate models of the inflation processthat is, ones that try to predict future headline inflation using only a single variable or a simple function of a single variable. ${ }^{3}$ I do not think this is a good metric for understanding whether core or headline is the right inflation measure on which to gauge monetary policy decisions, regardless of whether it holds up in the data or not. Presumably, we would want to use a fully specified model to try to predict headline inflation, the goal variable with respect to prices, in the United States. The full model would include measures of expected inflation, developments in the real economy, the stance of monetary policy (including the implicit inflation target), and other variables to help to predict future headline inflation outcomes. One could throw all of these variables out in favor of a single variable-core inflation-when trying to predict future headline inflation, but presumably then one would have a misspecified model of the inflation process in which a simple function of core inflation is acting as a proxy for all the variables that are supposed to be important for predicting future headline inflation. In this misspecified model, a simple function of core inflation may or may not have been a good predictor of future headline inflation over a particular time period, but so what? I do not think this really tells us anything about whether it is a good idea to key policy off of core inflation or not.

There is a version of this argument that might make more sense. That version works like this. Suppose we have a full model of the inflation process, one that includes expected inflation, measures of real activity, and measures of the stance of monetary policy. We then add core inflation as a variable to this model and assess the marginal predictive value of core inflation given all other variables. If the marginal value of adding core inflation in this context is positive, one might then have a claim that core inflation contains some "special" information over and above infor-

3 For a bivariate approach, see Kiley (2008). mation coming from the rest of the economy concerning the future course of inflation. ${ }^{4}$ I have not seen convincing evidence of this type.

But let's go ahead and consider the merely "wrong" part of this argument. Let's examine whether today's core inflation is a good predictor of future headline inflation in the context of a univariate forecasting model. I do not think the evidence is very clear on this question. A number of choices have to be made to even proceed in this area: the horizon over which to forecastlet's say, one year; the function of core inflation to use, such as a distributed lag, and the length of that lag; the data sample over which to test the hypothesis; and the measures of core and headline inflation to use. One recent research paper in this area investigates personal consumption expenditures (PCE) inflation and standard core PCE inflation (that is, PCE inflation less food and energy components) alongside other types of inflation measures over U.S. data from 1982 to $2005 .{ }^{5}$ In that paper, standard core PCE inflation performs relatively poorly as a predictor of future headline PCE inflation in most of the models discussed. ${ }^{6}$ Alternative measures of inflation do better, such as the trimmed mean measure produced by the Federal Reserve Bank of Dallas for PCE, which is shown in Figure $3 .{ }^{7}$ Analysis like this demonstrates that the idea that standard core inflation forecasts future headline inflation is far from an obvious conclusion given the U.S. data. ${ }^{8}$

Many intuitive discussions on the issue of core versus headline inflation contain the idea that noise should somehow be stripped out of the headline inflation measure in order to leave only the signal component. The energy price component of the headline price index often (depending

\footnotetext{
4 Rich and Steindel (2007) do include simple measures of slack in conjunction with various measures of core inflation in their statistical model. They find that no one measure of core inflation consistently outperforms others in out-of-sample tests.

5 See Smith (2010).

6 Similar results are discussed in Crone et al. (2008).

7 See Dolmas (2005). The Federal Reserve Bank of Cleveland constructs an analogous measure for CPI (Bryan and Cecchetti, 1994); see Figure 4.

8 See also the discussion in Faust and Wright (forthcoming), Thornton (2007), and DiCecio (2007).
} 


\section{Figure 3}

\section{PCE Inflation Measures: Headline, Core, and Trimmed Mean}

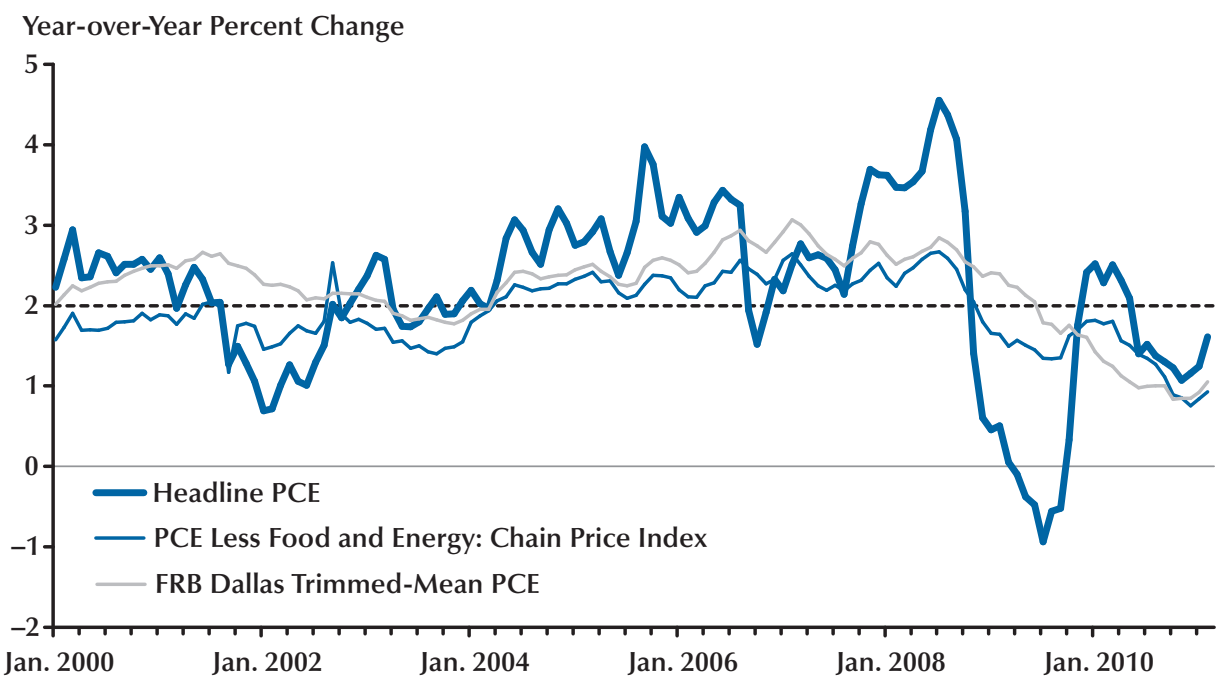

SOURCE: Bureau of Economic Analysis and Federal Reserve Bank of Dallas. Last observation April 2011.

\section{Figure 4}

\section{CPI Inflation Measures: Headline, Core, and Median}

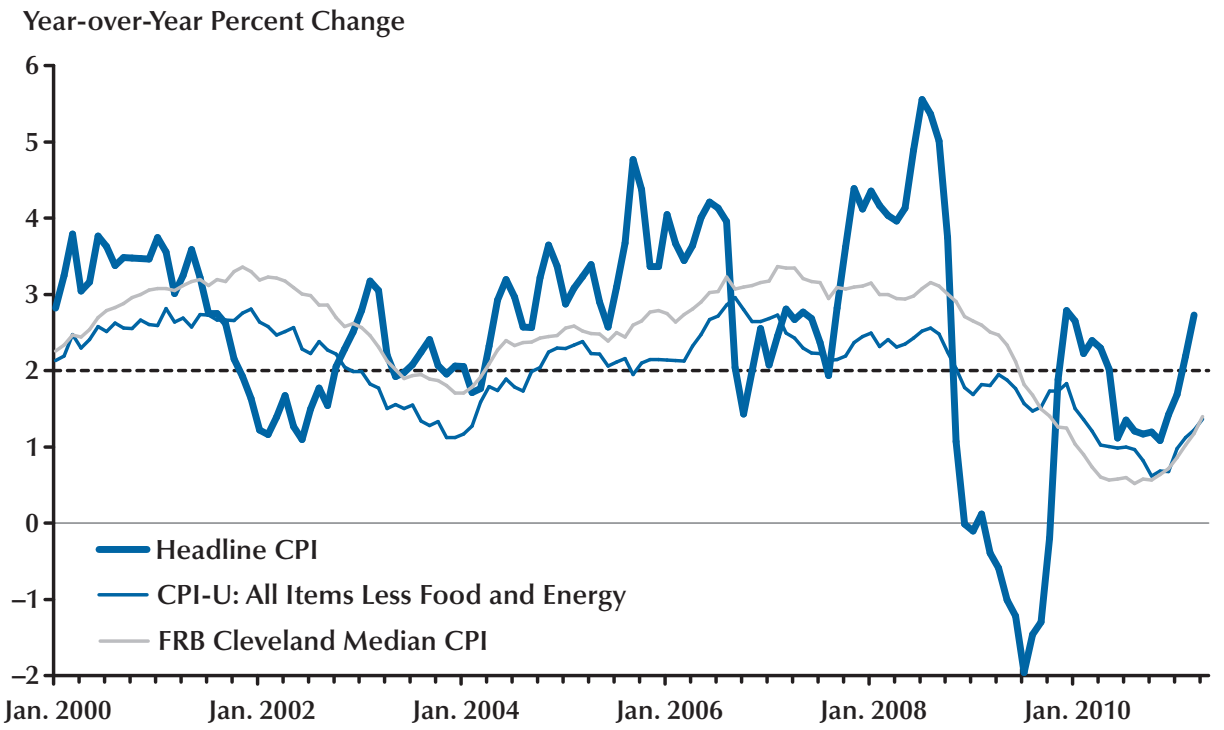

SOURCE: Bureau of Labor Statistics and Federal Reserve Bank of Cleveland. Last observation April 2011. 
on the time period) has the lowest signal-to-noise ratio, but the food component often does not have the second-lowest signal-to-noise ratio after 1984; for this reason, it is not clear that the food component should be routinely excluded on this basis. Also, the concept of a signal-to-noise ratio contains a notion that the noise component is stationary, whereas much of the contemporary worry about commodity prices is that relative price changes may be much more persistent going forward than they have been in the past. That brings us to the "relative price" argument for confining attention to core inflation.

\section{THE "RELATIVE PRICE" ARGUMENT}

The U.S. economy has many thousands of prices, and these prices are adjusting frequently. This is appropriate relative price adjustment. The prices are sending signals to households about what has become more expensive and less expensive at each moment in time. Think of the U.S. household sector as one unified household with a fixed budget constraint. Then if a particular price goes up, generally speaking another price has to fall or, alternatively, the expenditure shares on the two goods have to adjust so that the household can still meet its budget constraint. Either way, the household will adjust by changing behavior in response to the changing prices. The price indexes that are constructed by the Bureau of Labor Statistics (for the consumer price index [CPI]) and by the Bureau of Economic Analysis (for the PCE price index) already make adjustments for this behavior in various ways, especially in chain-weighted indexes that adjust expenditure weights more continuously. In this sense, relative price movements are already accounted for in the construction of existing indexes. Therefore, when the entire price index rises, it really does mean that there is inflation in the economy. Appealing to the idea of relative price change to explain increases in a price index is inappropriate in most circumstances, at least up to our ability to measure behavior induced by relative price changes correctly.
It is often asserted in discussions of this type that the Fed cannot help the fact that events occur around the world each day that affect various prices. Some prices are "out of our control." This is certainly true, but this is also true for every single price in the price index. Each one is affected by real supply and demand factors each day, none of which is susceptible to direct influence by the Federal Reserve. The only element of control the Fed has is over general movements in the entire price index, and only imprecisely over a period of quarters and years.

The key relative price changes in today's global economy are for energy and other commodities. Crude oil prices, in particular, are substantially higher in real terms than they were a decade ago and constitute a significant fraction of global expenditure. It is often asserted that energy prices cannot increase indefinitely-that a one-time rise in energy prices only temporarily contributes to inflation-and therefore that it makes sense to ignore such changes. However, the logic of relative prices suggests that if households are forced to spend more on energy consumption, then they have to spend less on the consumption of all other goods, thereby putting downward pressure on all other prices (and all other expenditure shares) in the economy. Ignoring energy prices would then understate the true inflation rate, as one would be focusing only on the prices facing downward pressure because of changing relative prices.

One might also reasonably question the "temporary" characterization of the shift in energy and other global commodity prices. It is certainly true that we should not expect energy prices to increase faster than the general price level without limit. But it is also true that there are wellknown examples of long-term secular trends in certain prices. One example is medical care prices, which for decades have generally increased faster than the headline CPI index (Figure 5). Another example is computing technology, where prices have more or less continuously declined per unit of computing power (Figure 6), even as other prices have continued to rise. So it is possibleand indeed it does happen-that whole sectors of the economy experience relative price change 


\section{Figure 5}

\section{Price of Medical Care (CPI: Medical Care) and Overall Price Level (CPI: All Items)}

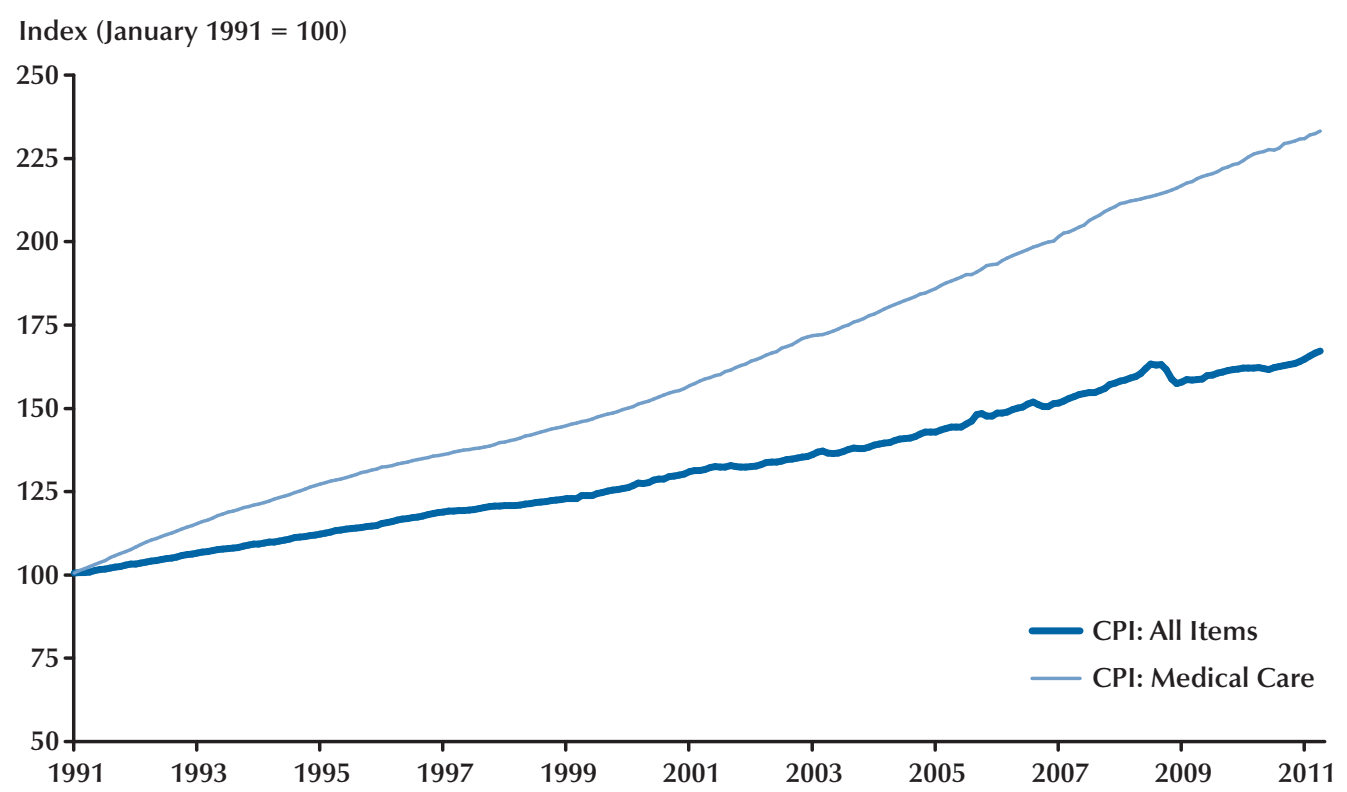

SOURCE: Bureau of Labor Statistics and author's calculations. Last observation April 2011.

over very long periods of time. From this perspective, it is at least a reasonable hypothesis that global demand for energy will outstrip increased supply over the coming decades as the giant economies of Asia, particularly India and China, reach Western levels of real income per capita. If that scenario unfolds, then ignoring energy prices in a price index will systematically understate inflation for many years. ${ }^{9}$

\section{SHOULD THE CENTRAL BANK TARGET A SUBSET OF PRICES?}

The last set of arguments in favor of a notion of core inflation is far more sophisticated, but also far less established. Up to now we have taken

9 The literature trying to disentangle the recessionary consequences of temporary oil-price shocks themselves from the consequences of the monetary policy response to those shocks is interesting but inconclusive. The results depend on many modeling details. See Kormilitsina (2011), Leduc and Sill (2004), and Dhawan and Jeske (2007). it for granted that the prices that households care about include all the prices that households actually have to pay. This suggests that our existing headline price indexes are the right ones to look at when considering what is best for households. Yet there is some interesting literature that asks the following question: Can we think of a theoretical world in which the central bank would want to target a subset of the prices faced by households, instead of all the prices, on the grounds that this policy would be preferred by the households themselves? We could then call changes in this subset of prices "core inflation."

The general answer is that this is indeed possible, and I believe future research in this area has to proceed in this direction. But these models, while interesting, are not ready for prime time, and so I think for now the best we central bankers can do is focus on the best measures of overall inflation we have and attempt to stabilize those.

The key feature of the literature in this area is that some prices are considered "sticky" (in a 
Figure 6

\section{Price of Computing Technology (Equipment and Software Chain Price Index) and Overall Price Level (GDP Chain Price Index)}

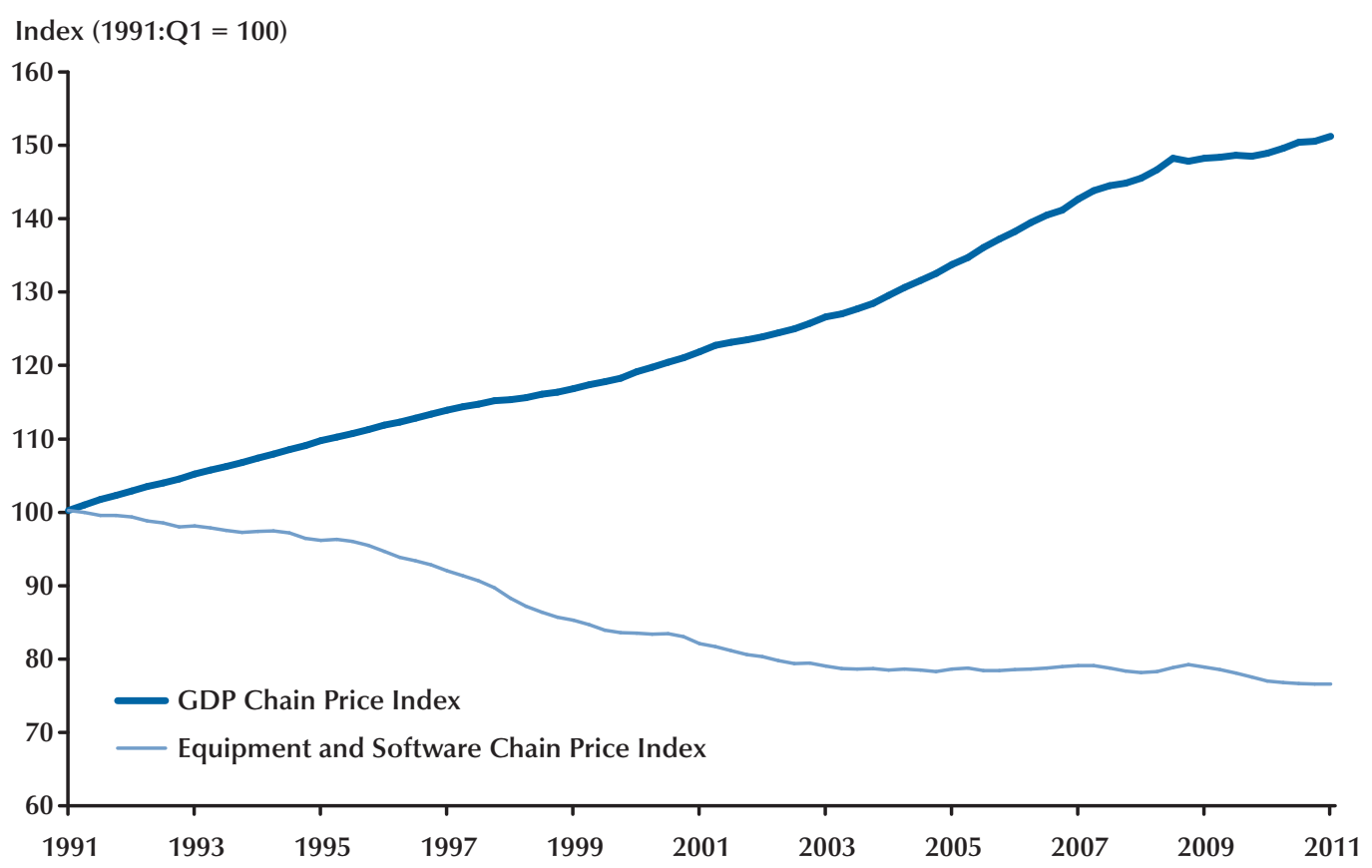

NOTE: GDP, gross domestic product.

sense made precise in the research), while other prices are fully flexible. ${ }^{10}$ For instance, one could posit that the energy price sector is characterized by fully flexible prices, while the rest of the economy is characterized by prices that do not adjust as readily to supply and demand disturbances and therefore are considered sticky. ${ }^{11}$ A typical result from the literature is that it is the sticky prices that matter more from the perspective of the households in the model, since those prices are not clearing markets as effectively as they could if prices were fully flexible. For this reason, the central bank might want to focus on a subset of

10 There is plenty of argument about how realistic it is to think that sticky price assumptions provide an appropriate foundation for monetary policy intervention. See, for instance, Kehoe and Midrigan (2007).

${ }^{11}$ For a discussion of some of the issues, see Bodenstein, Erceg, and Guerrieri (2008). prices, namely the sticky ones. One could think of changes in these sticky prices as core inflation. ${ }^{12}$

This idea has a long way to go to gain general acceptability, and it is certainly not widely endorsed even within macroeconomics. But at least it is one way to think about why it might be better to focus on a subset of prices instead of the entire price index.

There is an international version of this argument as well. ${ }^{13}$ In one area of research, there would be a sticky price sector in each country, and each central bank would provide the optimal monetary policy by focusing on the sticky price sector in its own country and ignoring import prices. This would divide up the prices in yet a

${ }^{12}$ See Eusepi, Hobijn, and Tambalotti (forthcoming) for a detailed discussion of an optimal "cost-of-nominal-distortions index" built with this idea in mind.

${ }^{13}$ See, for instance, Clarida, Galí, and Gertler (2002). 
different way, and perhaps one that makes a little bit of sense: Import prices would be excluded from domestic policy concerns because the foreign central bank would already be responding to the prices of its exports in setting its own policy (and exchange rates are flexible). Still, results like this depend on a lot of particular assumptions.

At this point in time, ideas like these are not widely entertained outside academic circles. I bring this literature up only to illustrate that there is interesting research about why it may be optimal to focus monetary policy on a subset of prices instead of a headline price index. But the existing literature tends to draw distinctions that are somewhat different from the way practitioners wish to view this issue. Most practitioners do not have in mind trying to divide up prices between those that are more "sticky" and those that are less so, or between domestic prices and import prices. ${ }^{14}$

\section{WHAT SHOULD WE DO?}

The theme of my remarks has been that U.S. monetary policy needs to de-emphasize core inflation. Core inflation is not the ultimate goal of monetary policy. I have considered four classes of arguments for a focus on core inflation and found all of them wanting. For this reason, I think the best the FOMC can do is to use headline inflation when looking at the price side of the dual mandate.

\footnotetext{
${ }^{14}$ For some actual data that attempt to distinguish sticky and flexible price inflation, see the Inflation Project at the Atlanta Fed (www.frbatlanta.org/research/inflationproject/data.cfm) and Bryan and Meyer (2010).
}

Core versus headline inflation has been a long-standing issue for the FOMC. The focus on core inflation in the United States seems to be more entrenched than in many other countries. I have argued that the older ideas justifying this focus have rotted over time-indeed, they probably made little sense from the start. The FOMC needs to get a better playbook on this question so that the Committee can reconnect with American households, who see price changes daily in many of the items the Committee seems to exclude from consideration in making monetary policy.

The headline measures of inflation were designed to be the best measures of inflation available. It is difficult to get around this fact with simple transformations of the price indexes. The Fed should respect the construction of the price indexes as they are and accept the policy problem it poses. To do otherwise may create the appearance of avoiding responsibility for inflation.

There is widespread agreement that headline inflation is the goal variable of monetary policy with respect to prices. Normally one would want to operate directly in terms of the goal variable whenever possible. The concept of core inflation suggests that somehow an intermediate target strategy with respect to price inflation is optimal for U.S. monetary policy. As I have outlined in this article, I do not think this has ever been convincingly demonstrated. In addition, the U.S. focus on core inflation tends to damage Fed credibility. As I noted in the introduction, many other central banks have solidified their position on this question by adopting explicit, numerical inflation targets in terms of headline inflation, thus keeping faith with their citizens that they will work to keep headline inflation low and stable. The Fed should do the same. 


\section{Bullard}

\section{REFERENCES}

Bodenstein, Martin; Erceg, Christopher J. and Guerrieri, Luca. "Optimal Monetary Policy with Distinct Core and Headline Inflation Rates.” Journal of Monetary Economics, October 2008, 55(Suppl. 1), pp. S18-S33.

Bryan, Michael F. and Cecchetti, Stephen G. "Measuring Core Inflation,” in N. Greg Mankiw, ed., Monetary Policy. Chicago: University of Chicago Press, 1994, pp. 195-215.

Bryan, Michael F. and Meyer, Brent. "Are Some Prices in the CPI More Forward Looking than Others? We Think So." Federal Reserve Bank of Cleveland Economic Commentary No. 2010-2, May 19, 2010; www.clevelandfed.org/Research/commentary/2010/2010-2.pdf.

Bullard, James. "Measuring Inflation: The Core Is Rotten.” Speech to the Money Marketeers of New York University, New York, NY, May 18, 2011; http://research.stlouisfed.org/econ/bullard/pdf/Measuring Inflation May 182011 FINAL.pdf.

Clarida, Richard H.; Galí, Jordi and Gertler, Mark L. "A Simple Framework for International Monetary Policy Analysis.” Journal of Monetary Economics, July 2002, 49(5), pp. 879-904.

Crone, Theodore M.; Khettry, N. Neil K.; Mester, Loretta J. and Novak, Jason A. "Core Measures of Inflation as Predictors of Total Inflation.” Working Paper No. 08-9, Federal Reserve Bank of Philadelphia, May 2008; www.philadelphiafed.org/research-and-data/publications/working-papers/2008/wp08-9.pdf.

Dhawan, Rajeev and Jeske, Karsten. "Taylor Rules with Headline Inflation: A Bad Idea.” Working Paper No. 2007-14, Federal Reserve Bank of Atlanta, July 2007; www.frbatlanta.org/filelegacydocs/wp0714.pdf.

DiCecio, Riccardo. “Inflation Disconnect?” Federal Reserve Bank of St. Louis Monetary Trends, July 2007; http://research.stlouisfed.org/publications/mt/20070701/cover.pdf.

Dolmas, Jim. “A Fitter, Trimmer Core Inflation Measure.” Federal Reserve Bank of Dallas Southwest Economy, Issue 3, May/June 2005; http://dallasfed.org/research/swe/2005/swe0503b.html.

Eusepi, Stefano; Hobijn, Bart and Tambalotti, Andrea. "CONDI: A Cost-of-Nominal-Distortions Index." (Forthcoming in American Economic Journal: Macroeconomics.)

Faust, Jon and Wright, Jonathan H. "Forecasting Inflation.” (Forthcoming in Graham Elliott and Allan Timmermann, eds., Handbook of Economic Forecasting. Volume 2. New York: Elsevier.)

Kehoe, Patrick J. and Midrigan, Virgiliu. "Sales and the Real Effects of Monetary Policy.” Working Paper No. 652, Federal Reserve Bank of Minneapolis, April 2007; www.minneapolisfed.org/research/WP/WP652.pdf.

Kiley, Michael T. "Estimating the Common Trend Rate of Inflation for Consumer Prices and Consumer Prices Excluding Food and Energy.” Board of Governors of the Federal Reserve System Finance and Economics Discussion Series No. 2008-38, July 2008; www.federalreserve.gov/pubs/feds/2008/200838/200838pap.pdf.

Kormilitsina, Anna. "Oil Price Shocks and the Optimality of Monetary Policy.” Review of Economic Dynamics, January 2011, 14(1), pp. 199-223.

Leduc, Sylvain and Sill, Keith. "A Quantitative Analysis of Oil-Price Shocks, Systematic Monetary Policy, and Economic Downturns.” Journal of Monetary Economics, May 2004, 51(4), pp. 781-808. 
Mishkin, Frederic S. "Headline Versus Core Inflation in the Conduct of Monetary Policy." Speech at the Business Cycles, International Transmission and Macroeconomic Policies conference, HEC Montreal, Montreal, Canada, October 20, 2007; www.federalreserve.gov/newsevents/speech/mishkin20071020a.htm.

Rich, Robert and Steindel, Charles. "A Comparison of Measures of Core Inflation.” Federal Reserve Bank of New York Economic Policy Review, December 2007, 13(3), pp. 19-38;

www.ny.frb.org/research/epr/07v13n3/0712rich.pdf.

Smith, Julie K. "PCE Inflation and Core Inflation.” Unpublished manuscript, Department of Economics, Lafayette College, January 2010.

Thornton, Daniel L. "Measure for Measure: Headline versus Core Inflation.” Federal Reserve Bank of St. Louis Monetary Trends, September 2007; http://research.stlouisfed.org/publications/mt/20070901/cover.pdf. 
